\title{
Are fancy acidic or neutral ligands really needed for synergism in ionic liquids? A comparative study of lanthanoids extraction in $\mathrm{CHCl}_{3}$ and an ionic liquid.
}

\author{
Maria Atanassova, ${ }^{\mathrm{a}, \mathrm{c}, \mathrm{d} *}$ Vanya Kurteva, ${ }^{\mathrm{b}}$ Lubomir Lubenov $^{\mathrm{b}}$, Sabi Varbanov ${ }^{\mathrm{b}}$, Isabelle Billard ${ }^{\mathrm{c}, \mathrm{d}}$
}

The study of trivalent lanthanoid ( $\mathrm{La}, \mathrm{Nd}, \mathrm{Eu}, \mathrm{Ho}$ and $\mathrm{Lu}$ ) extraction by two individual ligands: one acidic as pyrazolone derivative, 3-methyl1-phenyl-4-(4-phenylbenzoyl)-pyrazol-5-one (HL), and one neutral as 5,11,17,23-tetra-tert-butyl-25,26,27,28-tetrakis(dimethylphosphinoylmethoxy)calix[4]arene (S $\left.\mathrm{S}_{\mathrm{IV}}\right)$ was performed in $\mathrm{CHCl}_{3}$ and in one ionic liquid, IL (1-methyl-1,3-butylimidazoliumbis(trifluoromethanesulfonyl)imide $\left(\left[\mathrm{C}_{1} \mathrm{C}_{4} i m\right]\left[\mathrm{Tf}_{2} \mathrm{~N}\right]\right)$ in order to establish and examine the impact of the diluent onto the individual and synergistic extraction processes. Chloride aqueous medium and constant ionic strength $\mu=0.1 \mathrm{M}$ were set in both cases. The parameters of the extraction processes were determined. Comparison between the two diluents was made on the basis of: i) Composition of the extracted species: $\mathrm{LnL}_{3} \cdot \mathrm{HL}$ in $\mathrm{CHCl}_{3}$ vs $\mathrm{LnL}_{3}$ in IL with $\mathrm{HL}$ as a single extractant ( $\mathrm{L}^{-}$represents the $\mathrm{HL}$ anion), and $\mathrm{LnL}_{3} \cdot \mathrm{S}_{\mathrm{Iv}}$ in the presence of the phosphoruscontaining calix[4]arene in both diluents; and ii) Values of the equilibrium constants and the synergistic enhancements; the separation factors between metals were evaluated as well.

The IL medium appears far superior to the molecular solvent in terms of individual and overall synergistic extraction efficiencies. However, the huge differences in extraction efficiencies observed in $\mathrm{CHCl}_{3}$ for chemically different ligands are erased in the IL medium, thus modifying the lever arms on which chemists should rely in order to obtain even better extracting systems in ionic liquid media.

\section{Introduction}

The need for metals in pure forms made solvent extraction an expanding research field in the $20^{\text {th }}$ century. To this aim, synthetic chemists developed a tremendous amount of molecules and compounds which are able to efficiently perform extraction and separation of specific metallic ions from aqueous phases towards molecular solvents. However, by comparison to the huge amount of work performed aiming at enhancing extraction abilities through a careful design of various families of extracting agents, less attention has been paid to solvent formulation, mainly because the number of these is much more limited than the available library of extracting compounds. ${ }^{1}$ Another very important milestone in the improvement of the extraction process was the discovery of the synergistic effect. ${ }^{2}$ Synergism occurs when two ligands used in conjunction display better extraction efficiency than what could be expected from a simple addition of their individual effects. The first careful study of this phenomenon in 1958 was carried out by Blake et al. ${ }^{3}$ who found that $\mathrm{UO}_{2}{ }^{2+}$ is extracted synergistically by a mixture of dialkylphosphoric acid and a neutral organophosphorus reagent. Over the years, thorough investigation of this phenomenon has appeared and synergism has been found to be most effective when an acidic (HL) and a neutral (S) ligand are used together, ${ }^{4-6}$ although other combinations are also possible. It has been observed in the extraction of trivalent actinoids and lanthanoids that the synergistic enhancement is sometimes very high (up to $10^{8}$ ). ${ }^{6}$ This is one of the reasons for the great interest shown in the synergistic solvent extraction studies of this class of metal ions. Apart from the thermodynamical contribution (mixing extracting agents modifies each of their extracting properties, per se), the main reason for synergism is due to the occurrence of a new mixed species, containing both ligands. In the case of synergistic systems, $\mathrm{HL}$, thanks to its deprotonation, forms a neutral chelating compound with the metallic ion, while the neutral ligand, $\mathrm{S}$, expels the remaining water molecules in order to enhance solubility in the organic phase. In molecular solvents, it has been shown by one of us $^{7}$ that the more acidic $\mathrm{HL}$ is, and the less protonable $\mathrm{S}$ is, the greater the extraction is. In addition, many fragmentary studies hint strongly to the fact that the extent of synergistic enhancement depends also on the solvent employed $6,8,9$ and its polarity.

Under this frame, modern extraction chemistry focuses on supramolecules and the chemical engineering aspect pertaining to design and synthesis of new extractants, to be used in molecular solvents. ${ }^{10-14}$ Tremendous efforts have been put on improving the capabilities of both the acidic and the neutral components of synergistic systems. For example, trivalent lanthanoid ions are hard acids and therefore interact preferentially with hard bases, typical examples of which are oxygencontaining molecules or anions such as $\beta$-diketones. The acylpyrazoles can be considered as $\alpha$-substituted $\beta$-dicarbonyl compounds and their acid dissociation constants $\left(\mathrm{p} K_{\mathrm{a}}\right)$ are lower i.e. they possess much stronger acidic properties than 2 thenoyltrifluoroacetone ( $\mathrm{Htta}$ ) for example. ${ }^{15}$ Consequently, these chelating extractants have been extensively studied to investigate the synergism in solvent extraction chemistry both from theoretical and practical points of view. ${ }^{16,17}$ In particular, some of the authors of this work put a special emphasis on systematically unraveling the relationship between the nature of the para substituents of 4-aroyl-3-methyl-1-phenyl-pyrazol-5-ones and the effectiveness of the extraction process of lanthanoids. ${ }^{18}$ Such systematic studies aim at offering additional possibilities to empirically understand the requirements for an efficient extractant. Similarly, the unique molecular architecture of calixarenes (macrocycles made up of $\mathbf{n}$ phenolic units linked by methylene bridges) makes them a suitable platform for construction of host neutral molecules that can selectively bind a variety of guest substrates through introduction of suitable fragments on the upper or lower rim. ${ }^{19-21}$ The fascinating conformational and chemical reactivity of the calixarene systems has led to their use in a variety of applications including the development of efficient separation synergistic systems. ${ }^{18,22}$ However, depending on molecular solvents and nature of the acidic and neutral components of the synergistic system, either joint increase ${ }^{9}$ or opposite trends for extraction and selectivity ${ }^{18}$ can be obtained.

Nowadays, under the driving forces of the new European chemical regulation REACH (registration, evaluation, authorisation and restriction of chemicals) and of worldwide general ecological concerns, noxious volatile organic compounds (VOCs), such 
as the molecular solvents traditionally used in liquid/liquid extraction, tend to be banished from any chemical process. An interesting and elegant solution to this problem is the use of ionic liquids (ILs) as solvents. lonic liquids are not new compounds, they have been known for over a century but it took some years to realize their potential for technological applications. ${ }^{23}$ By definition, ILs are composed of cations (like ammonium, pyridinium, imidazolium derivatives etc.) and anions and have melting points below $100^{\circ} \mathrm{C}$, a low value as compared to those of molted salts (exs. $\mathrm{NaCl}: 801^{\circ} \mathrm{C} ; \mathrm{MgCl}_{2}$ : $712^{\circ} \mathrm{C} ; \mathrm{K}_{2} \mathrm{SO}_{4}: 1067^{\circ} \mathrm{C}$ ). These solvents exhibit several properties that make them attractive as potential basis for "green" separation processes, among them negligible vapor pressure, wide liquid range, non-flammability, and good thermal and radiation stability. ${ }^{23}$ Under the frame delineated above, another aspect of tremendous importance is their adjustable properties that can be tuned by an appropriate choice of the anion type or subtly altered by changing the length or number of alkyl groups appended to the cation. In other words, similarly to extracting agents that can be (and are) designed, ILs can be considered as designer solvents, offering a new play ground in view of enhanced extraction systems. ${ }^{24}$ Last but not least, it is well recognized that ILs offer unique liquid media for liquid/liquid extraction. ${ }^{14,25-27}$ Although a wide variety of ionic compounds are liquid at room temperature, those involving 1-alkyl-3-methyl-imidazolium cations and bis(trifluoromethylsulfonyl) imide anions have been the most investigated. ${ }^{25,28} \mathrm{ILs}$ based on the $\left(\mathrm{CF}_{3} \mathrm{SO}_{2}\right)_{2} \mathrm{~N}^{-}$anion are noncoordinating, and, in the absence of an extractant, most of the time do not significantly extract metal ions from aqueous phases, although some counter-examples providing huge distribution ratios could be found. ${ }^{29}$ As long as a ligand is dissolved in such ILs, tremendous extraction efficiencies are obtained, most of the time much higher than the corresponding values in traditional molecular solvents. ${ }^{30}$ In all these respects ILs are superior to molecular solvents. However, some severe drawbacks of ILs have been pinpointed, ${ }^{31}$ among which ILs' miscibility to the aqueous phase, which is highly dependent on the chemical conditions. ${ }^{32} \mathrm{~A}$ detailed balance of the advantages and drawbacks of ILs in view of an industrial application is out of the scope of this paper but is based, at least in part, on comparison of cost, efficiencies and selectivity. For the latter two aspects, as indicated above, ILs are interesting solvents.

We therefore undertook a systematic study of the synergistic solvent extraction and separation of lanthanoid(III) ions using mixtures of chelating and neutral extractants. Our first study confirmed ${ }^{33}$ that ILs dramatically enhance individual extracting abilities of both the acidic and neutral ligands we used but the synergistic effect, although significant, was rather disappointing, being lower in IL than in chloroform. In the present work, we now investigate the liquid-liquid extraction of some representatives of trivalent lanthanoid ions with 3-methyl-1-phenyl-4-(4-phenylbenzoyl)-pyrazol-5-one, HL, in the presence of the synergistic agent from the calix[n]arene family, $\mathbf{S}_{\mathrm{IV}}$, in an IL as well as in $\mathrm{CHCl}_{3}$. The aim of this study is to better understand the contributions of the acidic and the neutral extractant to synergism in IL phase, to compare these to the chloroform case and to derive, if possible, general rules concerning the optimization of synergistic couples of the (HL, S) type in ILs.

\section{Experimental}

\section{Reagents}

All reagents were purchased from Merck and Fluka and were used without any further purification. Fluka silica gel/TLC-cards 60778 with fluorescent indicator $254 \mathrm{~nm}$ were used for TLC chromatography.

The pyrazolone derivative, 3-methyl-1-phenyl-4-(4-phenylbenzoyl)-pyrazol-5-one (HL), ${ }^{34}$ was obtained according to an adapted literature procedure ${ }^{35}$ in excellent yield (Scheme 1). The experimental details and full characterization of the compound are given in the Supporting information together with the original 1D and 2D NMR spectra (Figs. S1-S9, Electronic Supplementary Information).

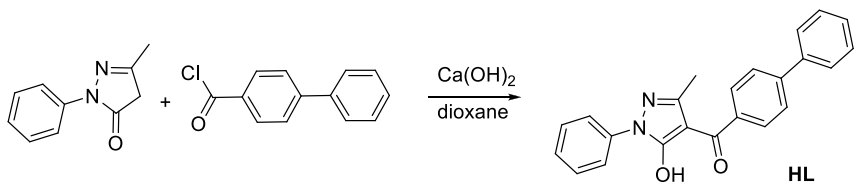

Scheme 1. Synthesis of 3-methyl-1-phenyl-4-(4-phenylbenzoyl)-pyrazol-5-one, HL.

The lower rim substituted calix[4]arene, $\mathrm{S}_{\mathrm{IV}}$, was synthesized according to the method already described ${ }^{36}$ (Electronic Supplementary Information), Fig. 1. 


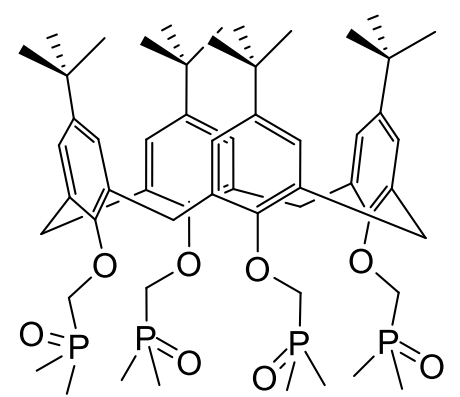

Fig. 1. Structural formula of 5,11,17,23-tetra-tert-butyl-25,26,27,28-tetrakis-(dimethylphosphinoylmethoxy)calix[4]arene, SIV.

The diluents were $\mathrm{CHCl}_{3}$ (Merck, p.a.) and 1-methyl-1,3-butylimidazolium-bis(trifluoromethanesulfonyl)imide, further noted as $\left[\mathrm{C}_{1} \mathrm{C}_{4} \mathrm{im}\right]\left[\mathrm{Tf}_{2} \mathrm{~N}\right]\left(99.5 \%\right.$, Solvionic, France). The IL was dried under vacuum following a previously published procedure ${ }^{37}$ prior to sample preparation. Stock solutions of metals with the concentration $2.5 \times 10^{-3} \mathrm{~mol} \mathrm{dm}^{-3}$ were prepared from their oxides (Fluka, puriss) by dissolving in concentrated hydrochloric acid and diluting with distilled ultra-pure water to the required volume. Arsenazo III (Fluka) was of analytical grade purity as were the other reagents used.

\section{Apparatus}

An S-20 Spectrophotometer Boeco (Germany) was used for measuring absorbances, a pH 211 HANNA (USA) digital pH meter was used for pH measurements and Orbital Shaker OS-20, Boeco, (Germany), $120 \mathrm{rpm}$ was used in the solvent extraction studies. The acidity of the aqueous phase at equilibrium was measured by a digital pH meter with an accuracy of $0.01 \mathrm{pH}$ units.

The NMR spectra were recorded on a Bruker Avance II+ 600 spectrometer (Rheinstetten, Germany) at $25^{\circ} \mathrm{C}$; the chemical shifts were quoted in ppm in $\delta$-values against tetramethylsilane (TMS) as an internal standard and against $\mathrm{H}_{3} \mathrm{PO}_{4}$ as external standard for ${ }^{31} \mathrm{P}$ spectra; the coupling constants were calculated in $\mathrm{Hz}$. The spectra were processed with Topspin 2.1 program. The melting point was determined in a capillary tube on SRS MPA100 OptiMelt (Sunnyvale, CA, USA) automated melting point system.

\section{Solvent Extraction Procedure}

The experiments were carried out using $10 \mathrm{~cm}^{3}$ volumes of aqueous and organic phases (chloroform). The samples were shaken mechanically for 45 minutes at room temperature $\left(22 \pm 2^{\circ} \mathrm{C}\right)$ which was sufficient to reach equilibrium. After the separation of the phases, the metal concentration in the aqueous phase was determined spectophotochemically using Arsenazo III. ${ }^{38}$ The concentration of the metal ion in the organic phase was calculated by subtraction of the determined amount in the aqueous phase from the total amount present. The ionic strength was maintained at $0.1 \mathrm{M}$ with $(\mathrm{Na}, \mathrm{H}) \mathrm{Cl}$. The initial concentration of the metals was $2.5 \times 10^{-4} \mathrm{~mol} \mathrm{dm}^{-3}$ in all experiments, prepared from the stock solutions.

In order to determine metal distribution ratios using ionic liquid $\left[\mathrm{C}_{1} \mathrm{C}_{4} i \mathrm{im}\right]\left[\mathrm{Tf}_{2} \mathrm{~N}\right]$ as organic media for La(III) extraction, $2.5 \mathrm{~cm}^{3}$ organic and aqueous phases of specific compositions identical to those used when $\mathrm{CHCl}_{3}$ was employed were stirred for 120 minutes at room temperature $\left(22 \pm 2^{\circ} \mathrm{C}\right)$, phases were separated and metal content was determined.

\section{Data analysis}

For each of the metals studied, the extraction data consist of ca. $35\left(\mathrm{CHCl}_{3}\right)$ or 23 (IL) D values, obtained in a wide range of $\mathrm{pH}, \mathrm{HL}$ and $\mathrm{S}$ concentrations. This mapping of the chemical domain allows determining the value of the extraction constant and of the $\mathrm{HL}, \mathrm{H}^{+}$and $\mathrm{S}$ stoichiometries. To this end, a dedicated Fortran routine was written and inserted in the powerful minimisation procedure available through the CERN libraries. The minimisation criterion was based on the $\chi^{2}$ values, defined as:

$$
\chi^{2}=\sqrt{\sum_{N}\left(D_{\exp }-D_{c a l}\right)^{2}} / N
$$

Where $D_{\text {exp }}$ and $D_{\text {cal }}$ are the experimental and calculated $D$ values and $N$ is the number of data points. All parameters were set free, but the stoichiometric coefficients were forced to be solely integers. The uncertainty on $\mathrm{K}$ was derived from an increase of $5 \%$ of the $\chi^{2}$ value. The equilibrium constants determined in this work are based on the assumption that the activity coefficients of the species do not change significantly under the experimental conditions i.e. they are concentration constants. 


\section{Results}

\section{Extraction of $\mathrm{Ln}$ (III) ions with 3-methyl-1-phenyl-4-(4-phenylbenzoyl)-pyrazol-5-one in $\mathrm{CHCl}_{3}$}

A wealth of previously published results for several trivalent elements and various solvents ${ }^{18,33,39-42}$ have shown that the extraction equilibria of lanthanoids with 4-acylpyrazolones can be described by the equation:

$$
\mathrm{Ln}^{3+}{ }_{(\mathrm{aq})}+4 \mathrm{HL}_{(\mathrm{o})} \leftrightarrow \mathrm{LnL}_{3} \cdot \mathrm{HL}_{(\mathrm{o})}+3 \mathrm{H}^{+}{ }_{(\mathrm{aq})}
$$

where $\mathrm{Ln}^{3+}$ denotes lanthanoid and the subscripts "aq" and "o" indicate the species in the aqueous and organic phase. The extraction constant, $K_{\mathrm{L}}$, is defined as:

$\boldsymbol{K}_{\mathrm{L}}=\frac{\left[\mathrm{LnL}_{3} \cdot \mathrm{HL}\right]_{(o)}\left[\mathrm{H}^{+}\right]_{(a q)}^{3}}{\left[\mathrm{Ln}^{3+}\right]_{(a q)}[\mathrm{HL}]_{(o)}^{4}}=\boldsymbol{D}_{\mathrm{L}} \frac{\left[\mathrm{H}^{+}\right]_{(a q)}^{3}}{[\mathrm{HL}]_{(o)}^{4}}$

where $D_{\mathrm{L}}$ is the lanthanoid distribution ratio. As seen from online resource Fig. S10 the plots of $\log D_{\mathrm{L}} \mathrm{Vs} \mathrm{pH}$ and $\log [\mathrm{HL}]$ are linear, with slopes very close to 3 and 4 , in accordance with eq.1.

In order to take into account possible deviations from this well-known equation, we decided to extend it to a more general form, as:

$$
\mathrm{Ln}^{3+}{ }_{(\mathrm{aq})}+(3+n) \mathrm{HL}_{(\mathrm{o})} \leftrightarrow \mathrm{LnL}_{3} \cdot \mathrm{nHL}_{(\mathrm{o})}+3 \mathrm{H}^{+}{ }_{(\mathrm{aq})}
$$

The extraction constant, $K_{\mathrm{L}}$, is thus defined as:

$K_{L}=\frac{\left[L n L_{3} \cdot n H L\right]_{(o)}\left[H^{+}\right]_{(a q)}^{\beta}}{\left[L n^{3+}\right]_{(a q)}[H L]_{(o)}^{(3+n)}}$

(2)

The relationship between $D_{\mathrm{L}}$, the lanthanoid distribution ratio, and $\mathrm{K}_{\mathrm{L}}$ is:

$D=K_{L} \frac{[H L]_{(o)}^{(3+n)}}{[H+]_{(a q)}^{3}}$

The experimental $D$ data were thus fitted according to eq. 2 bis, in which $K_{L}$ and $n$ are unknown parameters. As seen from online resource Table S1 the calculated values are in very good agreement with the experimental data. For all the metallic ions under study, we derive $n=1$. The extracted species is therefore of the form $\mathrm{LnL}_{3} \mathrm{HL}$ for all the lanthanoids of this work. The equilibrium constants for the extraction of lanthanoids with 3-methyl-1-phenyl-4-(4-phenylbenzoyl)-pyrazol-5-one are summarized in Table 1.

By contrast, the experimental data showed that the lanthanoid ions extraction with phosphorus-containing calix [4]arene, $\mathbf{S}_{\mathrm{IV}}$ used alone is negligible under the experimental conditions of the present study and applied concentrations $\left(1.2 \times 10^{-3} \div 6 \times 10^{-4}\right.$ $\mathrm{M})$ in $\mathrm{CHCl}_{3}$.

Table 1. Values of the equilibrium constants $K_{\mathrm{L}}, K_{\mathrm{L}, \mathrm{S}}$ and $B_{\mathrm{L}, \mathrm{S}}$, synergistic coefficients and separation factors for lanthanoids

\begin{tabular}{|c|c|c|c|c|c|c|c|}
\hline \multirow[t]{2}{*}{ Ln } & \multirow{2}{*}{$\begin{array}{l}K_{\mathrm{L}} \\
\log K_{\mathrm{L}}\end{array}$} & \multirow{2}{*}{$\begin{array}{l}K_{\mathrm{L}, \mathrm{SIV}} \\
\log K_{\mathrm{L}, \mathrm{SIV}}\end{array}$} & \multirow[t]{2}{*}{$\log \beta$} & \multirow[t]{2}{*}{ S.C. } & \multicolumn{3}{|c|}{ SF } \\
\hline & & & & & & $\mathrm{HL}$ & $\mathrm{HL}-\mathrm{S}_{\mathrm{IV}}$ \\
\hline La & $\begin{array}{l}(4.9 \pm 0.9) \times 10^{-7} \\
-6.31\end{array}$ & $\begin{array}{l}(5.8 \pm 0.6) \times 10^{-2} \\
-1.24\end{array}$ & 5.07 & 3.54 & $\mathrm{Nd} / \mathrm{La}$ & 2.4 & 7.9 \\
\hline $\mathrm{Nd}$ & $\begin{array}{l}(1.5 \pm 0.2) \times 10^{-6} \\
-5.82\end{array}$ & $\begin{array}{l}(0.43 \pm 0.06) \\
-0.37\end{array}$ & 5.45 & 4.07 & $\mathrm{Eu} / \mathrm{Nd}$ & 1.8 & 2.5 \\
\hline $\mathrm{Eu}$ & $\begin{array}{l}(1.7 \pm 0.3) \times 10^{-6} \\
-5.77\end{array}$ & $\begin{array}{l}(1.1 \pm 0.5) \\
0.04\end{array}$ & 5.81 & 4.20 & $\mathrm{Ho} / \mathrm{Eu}$ & 3.9 & 2.2 \\
\hline Ho & $\begin{array}{l}(1.3 \pm 0.2) \times 10^{-5} \\
-4.89\end{array}$ & $\begin{array}{l}(2.4 \pm 0.5) \\
0.38\end{array}$ & 5.27 & 3.94 & Lu/Ho & 2.4 & 2.0 \\
\hline Lu & $\begin{array}{l}(2.8 \pm 0.3) \times 10^{-5} \\
-4.55\end{array}$ & $\begin{array}{l}(5.1 \pm 0.9) \\
0.70\end{array}$ & 5.25 & 3.88 & & & \\
\hline
\end{tabular}
extraction with mixtures $\mathrm{HL}-\mathrm{S}_{\text {IV }}$ using $\mathrm{CHCl}_{3}$.

S.C.: $\mathrm{pH}=3.10,[\mathrm{HL}]=1.5 \times 10^{-2} \mathrm{~mol} / \mathrm{dm}^{3},\left[\mathrm{~S}_{\mathrm{IV}}\right]=6 \times 10^{-4} \mathrm{~mol} / \mathrm{dm}^{3}$. 
As it is well-known that the chelating agents are weak acids and the neutral donors are bases, there is a possibility for interaction between the extractants which will reduce the concentrations of free ligands during liquid-liquid extraction. ${ }^{7}$ The unfavorable role of the extractant interaction was noted by Zhang. ${ }^{43}$ The author has concluded that the antagonistic effect found for the extraction of $\mathrm{Pd}(\mathrm{II})$ with mixtures of 3-methyl-1-phenyl-4-propinoyl-pyrazol-5-one and a tertiary alkylamine can be expressed by a decrease of the pyrazolone concentration in the organic phase $\left(\mathrm{CHCl}_{3}\right.$ medium) due to the formation of an associated species HPMPP.NR $R_{1} R_{2} R_{3}$ through hydrogen bonding. The interactions between chelating $(\mathbf{H L})$ and neutral $\left(\mathbf{S}_{\mathrm{IV}}\right)$ extractants employed in the present work were thus studied by NMR spectra in deuterochloroform, the same solvent used in the extraction. The spectra of pyrazolone (HL) show sharp and well defined signals compatible with pure enol form, which were not changed by the addition of calixarene $\left(\mathbf{S}_{\mathrm{IV}}\right)$. All signals in proton (Figs. S11 and S12), carbon (Figs. S13 and S14) and phosphorus spectra (Fig. S15) of $\mathbf{S}_{\mathrm{IV}}, \mathbf{H L}$ and their mixtures possess the same chemical shifts. The latter is an indication that no interactions between the extracting system components occur in the organic phase. The cross peaks in ROESY experiments (Figs. S16 and S17), where only weak interactions between methyl group at position $3\left(\mathrm{CH}_{3}-3\right)$ of $\mathrm{HL}$ and t-Bu methyl groups and one of the bridged methylene protons of calixarene were detected (Fig. 2), confirm this result.

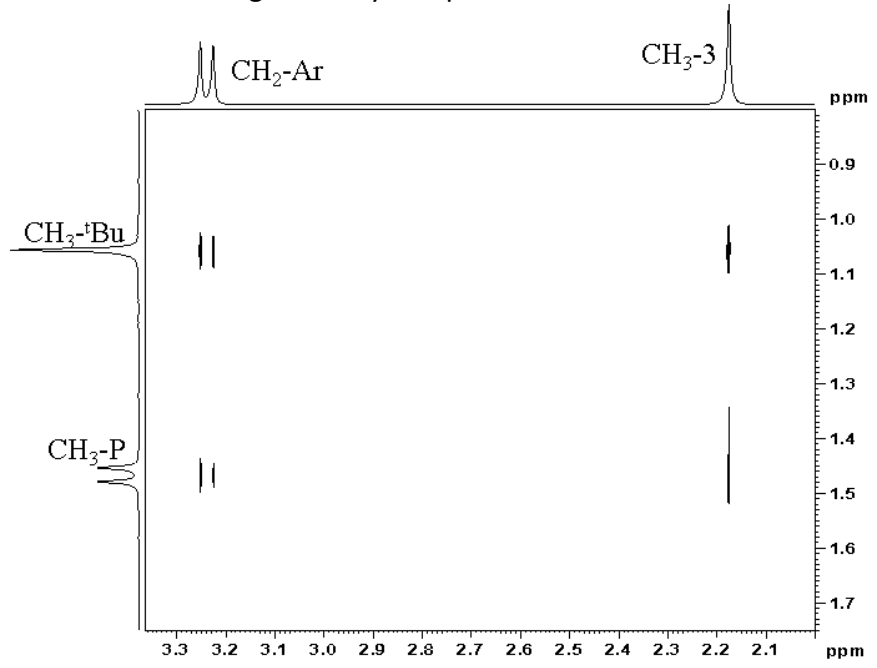

Fig. 2. A part of the strong field area of ${ }^{1} \mathrm{H}-{ }^{1} \mathrm{H}$ ROESY spectrum of $\mathrm{S}_{\mathrm{IV}}: \mathrm{HL} 1: 1$ mixture in $\mathrm{CDCl}_{3}$.

The same pattern was observed in $\mathbf{S}_{\mathrm{IV}}$ and 4-methyl and 4-fluorobenzoyl pyrazolone systems, ${ }^{18}$ which shows that the interactions between calixarene, applied in current study, and pyrazolones are not dependent on the pyrazolone aroyl group substituent.

On the contrary, when calixarenes, possessing two and three dimethylphosphinoylpropoxy groups at the narrow rim, and 4trifluoromethylbenzoyl pyrazolone $\left(\mathrm{HL}^{\prime}\right)$ systems were investigated, ${ }^{33}$ slight interactions were detected, the methyl group at position 3 and quaternary $\mathrm{C}_{\mathrm{q}}-3$ signals of $\mathrm{HL}^{\prime}$ and calixarene phosphorus being the most shifted. As seen in Fig. 3, the chemical shifts of these signals, $\mathrm{C}_{\mathrm{q}}-3$ at $148.02 \mathrm{ppm}$ and $\mathrm{CH}_{3}$ at $16.22 \mathrm{ppm}$ of $\mathrm{HL}$ and ${ }^{31} \mathrm{P}$ of $\mathrm{S}_{\mathrm{IV}}$ at $38.65 \mathrm{ppm}$, are not influenced by the mixing. A comparison between these systems permits to suggest that the free $\mathrm{OH}$ groups of calixarene are involved in the interactions with pyrazolone chelating arm, while phosphinoyl units do not participate.

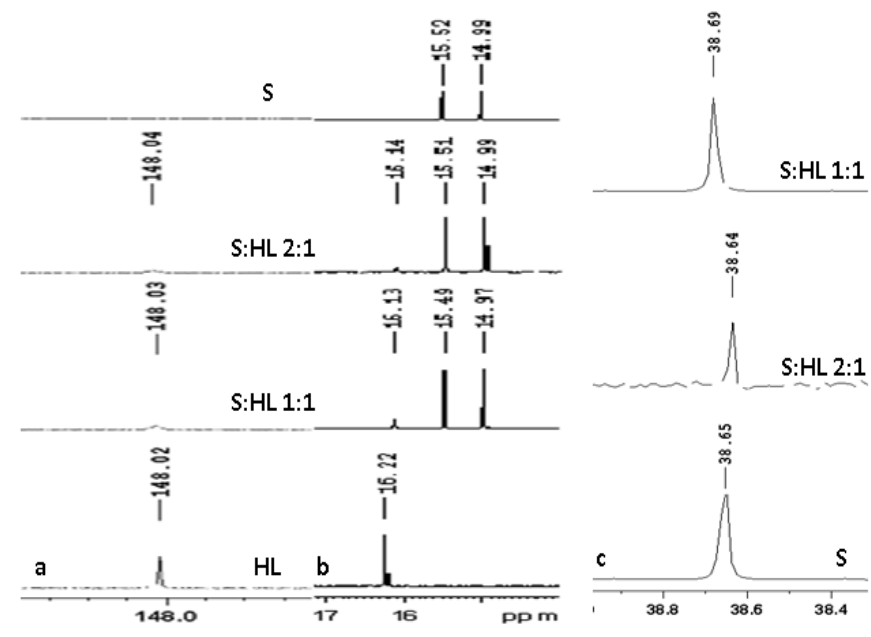

Fig. 3. $\mathrm{C}_{\mathrm{q}}-3$ (a) and $\mathrm{CH}_{3}$ (b) $\mathrm{HL}^{13} \mathrm{C}$ and ${ }^{31} \mathrm{P} \mathrm{S}_{\mathrm{IV}}$ (c) signals in $\mathrm{CDCl}_{3}$.

Synergistic solvent extraction and separation of $\mathrm{Ln}^{3+}$ ions using $\mathrm{CHCl}_{3}$ as a diluent. 
The experimental data for the synergistic solvent extraction of the lanthanoid(III) ions with mixtures of $\mathrm{HL}$ and 5,11,17,23tetra-tert-butyl-25,26,27,28-tetrakis-(dimethylphosphinoylmethoxy) calix[4]arene, $\mathrm{S}_{\mathrm{IV}}$, were fitted to the mathematical expression relating $D$ to $K_{L, S}, n$ and $p$. For all the metallic ions investigated, the fits are satisfactory and lead to $n=0(3 \mathrm{HL}$ entities only) and $p=1$. Figs. 4 and 5 illustrate the fitting results under two forms: fitted versus experimental $D$ values ( $N d$ case, fig. 4); D versus pH or $\log D_{\mathrm{L}, \mathrm{SIV}}$ versus pH (all Ln, fig. 5) respectively. For fig. 5, you have to choose the best display (normal or log plot).

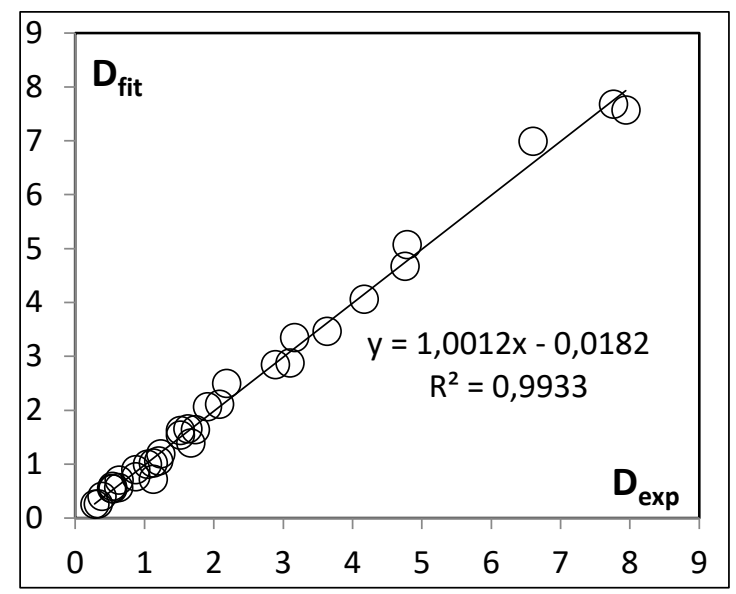

Fig. 4. Fitted versus experimental $\mathrm{D}$ values for $\mathrm{Nd}$ extraction data in $\mathrm{CHCl}_{3}$, using $\mathrm{HL}-\mathrm{S}_{\mathrm{IV}}$ mixture.

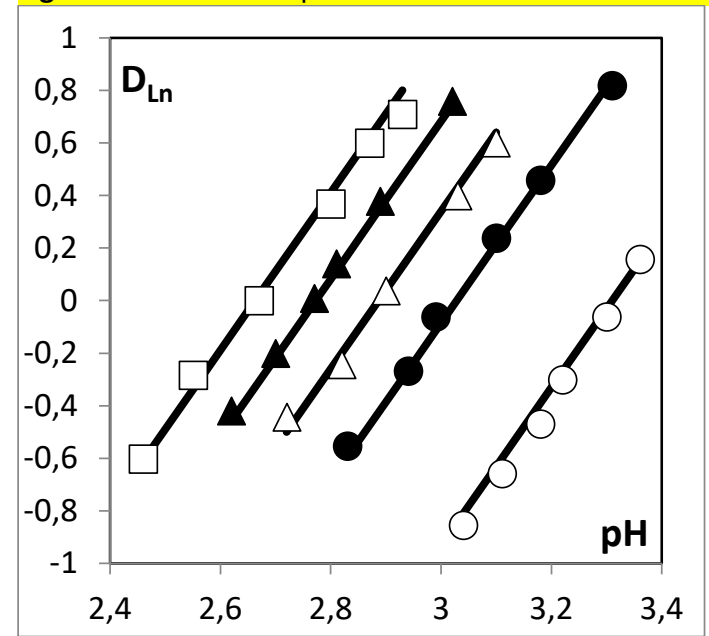

Fig. 5. Distribution ratio for the extraction of $\mathrm{Ln}(\mathrm{III})$ ions towards $\mathrm{CHCl}_{3}$, using $[\mathrm{HL}]=1.5 \times 10^{-2} \mathrm{M}$ and $\left[\mathrm{S}_{\mathrm{IV}}\right]=6 \times 10^{-4} \mathrm{M}$. Symbols: experimental data. $\square$ : Lu; $\boldsymbol{\Delta}: \mathrm{Ho} ; \Delta$ : Eu; $\bullet$ : Nd; O: Lu. Solid lines: fitted values.

The experimental data for the synergistic solvent extraction of the lanthanoid(III) ions with mixtures of $\mathbf{H L}$ and 5,11,17,23tetra-tert-butyl-25,26,27,28-tetrakis-(dimethylphosphinoylmethoxy) calix[4]arene, $\mathbf{S}_{\mathrm{IV}}$ are given in Figs. S18-S20 as well according slope analysis method. The plots of $\log D_{\mathrm{L}, \mathrm{SIV}}$ versus $\mathrm{pH}$ and $\log [\mathrm{HL}]$ are linear with slope close to three and the plots of $\log D_{\mathrm{L}, \mathrm{SIV}} \mathrm{vs}$. $\log \left[\mathrm{S}_{\mathrm{IV}}\right]$ with slope close to one. Therefore, in the presence of phosphorus-containing calix[4]arenes, the lanthanoid extraction can be expressed by the equation:

$\mathrm{Ln}^{3+}{ }_{(\mathrm{aq})}+3 \mathrm{HL}_{(\mathrm{o})}+\mathrm{S}_{(\mathrm{o})} \leftrightarrow \mathrm{LnL}_{3} \cdot \mathrm{S}_{(\mathrm{o})}+3 \mathrm{H}^{+}{ }_{(\mathrm{aq})}$

The complex $\mathrm{LnL}_{3} \cdot \mathrm{S}_{\mathrm{IV}}$ with coordination number probably 10 (six oxygen atoms from three bidentate $\mathrm{L}^{-}$anions and four dentate $S_{\mathrm{IV}}$ ligand) has been extracted. The involvement of one molecule of the phosphorus containing calix[4]arene in the synergistic species when trivalent lanthanoids are extracted with chelating extractants from 4-aroyl-3-methyl-1-phenylpyrazol-5-one's family have also been found previously. ${ }^{18}$ The stoichiometry 1:3:1 of isolated similar mixed solid complexes was obtained by Atanassova et al. ${ }^{9}, 44$ indicating uniform interactions of all four calixarene's ligating groups with $\operatorname{Ln}($ III) ions. Ramirez et al. ${ }^{45}$ have obtained suitable for X-ray crystallography single tetragonal crystals with composition [ $\left.\operatorname{LaB}_{4} \mathrm{bL}^{4}\left(\mathrm{H}_{2} \mathrm{O}\right)_{5}\right]$, (where $\mathrm{B}_{4} \mathrm{bL}^{4}$ is the compound $\mathrm{S}_{\mathrm{IV}}$ in the present study), in which $\mathrm{La}$ (III) ion is not encapsulated into calixarene cavity and is coordinated by the four $\mathrm{O}(\mathrm{P})$ atoms. 
Taking into account that the partition of pyrazolones ${ }^{17}$ and the calixarene ${ }^{36}$ toward the aqueous phase is very low, the formation of mixed complexes in the organic phase can be described by the following equation:

$$
\mathrm{LnL}_{3} \cdot \mathrm{HL}_{(\mathrm{o})}+\mathrm{S}_{(\mathrm{o})} \leftrightarrow \mathrm{LnL}_{3} \cdot \mathrm{S}_{(\mathrm{o})}+\mathrm{HL}
$$

The equilibrium constant $\boldsymbol{B}_{\mathrm{L}, \mathrm{S}}$ for the organic phase synergistic reaction can be determined as:

$$
\log \beta_{\mathrm{L}, \mathrm{S}}=\log K_{\mathrm{L}, \mathrm{S}}-\log K_{\mathrm{L}}
$$

The values of the equilibrium constants $K_{\mathrm{L}, \mathrm{S}}$ and $B_{\mathrm{L}, \mathrm{S}}$ derived from the fit of the experimental data are given in Table 1. The equilibrium constants experimentally determined in this work are based on the assumption that the activity coefficients of the species do not change significantly under the experimental conditions i.e. they are concentration constants. The data presented in Table 1 show that the addition of $\mathrm{S}_{\mathrm{IV}}$ to the system $\mathrm{Ln}(\mathrm{III})-\mathrm{HL}$ leads to a very large increase of the values of $K_{\mathrm{L}, \mathrm{S}}$ in comparison with those of $K_{\mathrm{L}}$ (4-5 orders of magnitude). The values of $\log K_{\mathrm{L}, \mathrm{S}}$ increase from La to Lu in agreement with the increasing charge density resulting from the lanthanoid contraction.

The synergistic enhancement produced by HL-S mixture can be determined using the synergistic coefficients (S.C.). They were calculated as: S.C. $=\log \left[D_{1,2} /\left(D_{1}+D_{2}\right)\right]$ where $D_{1}, D_{2}$ and $D_{1,2}$ are the distribution coefficients of the metal with the two extractants taken separately and with their mixture, respectively. The values of the synergistic coefficients are listed in Table 1. It is seen that the lanthanoids are extracted synergistically (S.C.>0). The addition of 5,11,17,23-tert-butyl-25,26,27,28tetrakis(dimethylphosphinoylmethoxy)calix[4]arene to the chelating extractant improves the extraction efficiency of the lanthanoid ions and produces large synergistic effects (about four orders of magnitude). The synergistic enhancement established in the present study is higher than those found in our previous investigations dealing with the lanthanoid extraction with acylpyrazolone chelating extractants with different substituents in para-position $\left(-\mathrm{F},-\mathrm{CH}_{3},-\mathrm{CF}_{3}\right) .{ }^{18,33,46}$ Finally, the separation of the lanthanoids using HL-S IV mixture can be assessed by the separation factors (S.F.) calculated as a ratio of the equilibrium constants $K_{\mathrm{L}, \mathrm{S}}$ of the two lanthanoids (the heavier and the lighter one). Their values are given in Table 1, too. The obtained SFs for the extraction of the investigated lanthanoid ions for pairs Eu/ $\mathrm{Nd}, \mathrm{Ho} / \mathrm{Eu}$ and Lu/Ho are similar for three synergistic mixtures using different para-substituent of 4-aroyl-3-methyl-1-phenyl-pyrazol-5-ones in combination with the same synergistic agent, ${ }^{18}$ but they are twice higher for the light pair $\mathrm{Nd} / \mathrm{La}$ in comparison with the cases when pyrazolone molecule was used with $-\mathrm{F}$ and $-\mathrm{CH}_{3}$ aroyl substituents. Synergism occurring by addition of $\mathrm{S}_{\mathrm{IV}}$ is accompanied with a decrease in the S.F. values through the Ln series. Such opposite effects (gain in extraction efficiency but lower selectivity for synergistic mixtures, as compared to the acidic extractant alone along the Ln series) are quite common in traditional molecular solvents ${ }^{47-49}$ although in some cases, synergism also leads to better selectivity. ${ }^{9}$

\section{Extraction and synergism of La ${ }^{3+}$ ions in 1-methyl-1,3-butylimidazolium-bis(trifluoromethanesulfonyl)imide}

The $\log D$ values of $\mathrm{La}(\mathrm{III})$ using IL phase with $\mathbf{H L}$ and $\mathrm{S}_{\mathrm{IV}}$ alone are plotted as a function of the aqueous phase $\mathrm{pH},[\mathrm{HL}]$ and $\left[\mathrm{S}_{\mathrm{IV}}\right]$ concentrations. These plots are shown in Fig. S21.

From the obtained results the extraction process of $\mathrm{La}(\mathrm{III})$ with $\mathrm{HL}$ in $\left[\mathrm{C}_{1} \mathrm{C}_{4} \mathrm{im}\right]\left[\mathrm{Tf}_{2} \mathrm{~N}\right]$ can be described by the equation:

$$
\mathrm{Ln}^{3+}{ }_{(\mathrm{aq})}+(3+\mathrm{n}) \mathrm{HL}{ }_{(\mathrm{o})} \leftrightarrow \mathrm{LnL}_{3(\mathrm{o})}+3 \mathrm{H}^{+}{ }_{(\mathrm{aq})}
$$

The fit of the experimental data leads to $n=0$. The fitted values of the equilibrium constants are presented in Table 2 . The present results show great change in the extraction efficiency of the studied lanthanoid at approximately 2 times lower concentration of the chelating extractant (3-methyl-1-phenyl-4-(4-phenylbenzoyl)-pyrazol-5-one). Moreover, the stoichiometry of the $\mathrm{La}(\mathrm{III})-\mathrm{HL}$ complex in IL and in traditional organic solvent $\mathrm{CHCl}_{3}$ is different.

In order to compare the selectivity using $\mathrm{HL}$ and different organic medium for the extraction ( $\mathrm{CHCl}_{3}$ or IL), a light (La), medium $(\mathrm{Eu})$ and heavy $(\mathrm{Lu})$ ions, are chosen as representatives of the beginning, middle and the end of the $4 \mathrm{f}$-series. For this purpose the liquid-liquid extraction of $\mathrm{Eu}(\mathrm{III})$ and $\mathrm{Lu}(\mathrm{III})$ was performed in $\left[\mathrm{C}_{1} \mathrm{C}_{4} i \mathrm{~m}\right]\left[\mathrm{Tf}_{2} \mathrm{~N}\right]$ with $7 \times 10^{-3} \mathrm{~mol} / \mathrm{dm}^{3} \mathrm{HL}$ (Fig. S22). The separability of $\mathrm{Lns}$ was assessed as a ratio of the corresponding $D_{\mathrm{L}}$ values and the calculated separation factors are given in Table 3. Huge separation factors are obtained for the Eu/La and Lu/La couples in the IL phase, with a much lower SF values for Lu/Eu which nevertheless could be qualified as satisfactory in molecular solvents.

Table 2. Values of the equilibrium constants $K_{\mathrm{L}}, K_{\mathrm{S}}$ and $K_{\mathrm{L}, \mathrm{S}}$ and synergistic coefficient for $\mathrm{La}(\mathrm{III})$ extraction with $\mathrm{HL}, \mathrm{S}_{\mathrm{IV}}$ and $\mathrm{HL}-$ SIv mixture using IL.

\begin{tabular}{|l|l|l|l|l|}
\hline$K_{\mathrm{L}}, \log K_{\mathrm{L}}$ & $\log K_{\text {SIV }}$ & $K_{\mathrm{L}, \mathrm{SIV}}, \log \kappa_{\mathrm{L}, \mathrm{SIV}}$ & $\log \beta_{\mathrm{L}, \mathrm{SIV}}$ & $\mathrm{SC}$ \\
\hline$(6.0 \pm 1) \times 10^{-2}$ & 3.38 & $(3.0 \pm 0.2) \times 10^{3}$ & 5.3 & 2.45 \\
-2.2 & & 3.0 & & \\
\hline
\end{tabular}

S.C.: $\mathrm{pH}=2.40,[\mathrm{HL}]=5 \times 10^{-3} \mathrm{~mol} / \mathrm{dm}^{3},\left[\mathrm{~S}_{\mathrm{IV}}\right]=7 \times 10^{-4} \mathrm{~mol} / \mathrm{dm}^{3}$.

Table 3. Values of separation factors of $\mathrm{Eu} / \mathrm{La}, \mathrm{Lu} / \mathrm{Eu}$ and $\mathrm{Lu} / \mathrm{La}$ pairs obtained with $\mathrm{HL}$ alone in $\mathrm{CHCl}_{3}$ and IL medium $\left([\mathrm{HL}]=7 \times 10^{-3} \mathrm{~mol} / \mathrm{dm}^{3}, \mathrm{pH}=2.35\right)$. 


\begin{tabular}{|l|l|l|}
\hline Ln pair & $\mathrm{CHCl}_{3}$ & IL \\
\hline $\mathrm{Eu} / \mathrm{La}$ & 4.4 & 31.6 \\
\hline $\mathrm{Lu} / \mathrm{Eu}$ & 9.7 & 5.4 \\
\hline $\mathrm{Lu} / \mathrm{La}$ & 42.6 & 170.6 \\
\hline
\end{tabular}

The calixarene, $\left(\mathrm{S}_{\mathrm{VV}}\right)$ dissolved in $\left[\mathrm{C}_{1} \mathrm{C}_{4} \mathrm{im}\right]\left[\mathrm{Tf}_{2} \mathrm{~N}\right]$ provides high extractability for $\mathrm{La}^{3+}$ ion as it is seen from Fig. S21. In $\left[\mathrm{C}_{1} \mathrm{C}_{4} i \mathrm{~m}\right]\left[\mathrm{Tf}_{2} \mathrm{~N}\right]$, a slope of 1 obtained from the plot indicates that one molecule of $\mathbf{S}_{\mathrm{IV}}$ is involved in the extraction step. The calculated value of $\log K_{\mathrm{S}}$ as $\log K_{\mathrm{S}}=\log D_{\mathrm{S}}-\log [\mathrm{S}]$ is also presented in Table 2. In line with other results for different Eu extraction systems in ionic liquids ${ }^{33,50}$ we therefore propose that La extraction by $\mathrm{S}_{\mathrm{IV}}$ alone in $\left[\mathrm{C}_{1} \mathrm{C}_{4} \mathrm{im}\right]\left[\mathrm{Tf}_{2} \mathrm{~N}\right]$ proceeds through cationic exchange according to the following equilibrium:

$\mathrm{Ln}^{3+}{ }_{(\mathrm{aq})}+\mathrm{S}_{(\mathrm{o})}+3 \mathrm{C}_{1} \mathrm{C}_{4} \mathrm{im}^{+}{ }_{(\mathrm{o})} \leftrightarrow[\mathrm{LnS}]^{3+}{ }_{(\mathrm{o})}+3 \mathrm{C}_{1} \mathrm{C}_{4} \mathrm{im}^{+}{ }_{(\mathrm{aq})}$

The liquid-liquid extraction of trivalent rare earth ions by neutral calix[n]arenes usually proceeds via formation of a complex ion pair of stoichiometry 1:1, metal:ligand in molecular solvents: $\left(\mathrm{CHCl}_{3}\right)^{51},\left(\mathrm{CHCl}_{3}, 1,2\right.$-dichloroethane, nitrobenzene). ${ }^{52}$ The $\log D$ values of $\mathrm{La}(\mathrm{III})$ using IL phase with $\mathrm{HL}-\mathrm{S}_{\mathrm{IV}}$ mixture are plotted as a function of the aqueous phase $\mathrm{pH}$ and $[\mathrm{HL}]$ or [S $\left.\mathrm{S}_{\mathrm{IV}}\right]$ concentration in Fig. $\mathrm{S} 23$ and $\log \mathrm{D}$ vs. $\mathrm{pH}$ in fig. 6 . For the synergistic mixture $\mathrm{HL}-\mathrm{S}_{\mathrm{IV}}$, we observe similar extraction mechanism towards $\mathrm{La}(\mathrm{III})$ ions using $\left[\mathrm{C}_{1} \mathrm{C}_{4} \mathrm{Im}^{+}\right]\left[\mathrm{Tf}_{2} \mathrm{~N}^{-}\right]$and $\mathrm{CHCl}_{3}$ as diluents, as described by reaction (4) and in agreement with our previous study 33 dealing with closely related synergistic systems. The overall equilibrium constant $K_{\mathrm{L}, \mathrm{S}}$ for La(III) obtained with the $\mathrm{HL}-\mathrm{S}_{\mathrm{IV}}$ mixture using $\mathrm{IL}$ is approximately 4.7 orders of magnitude higher than that obtained using $\mathrm{CHCl}_{3}$ as a diluent. The mixed complex formed in the organic IL phase can be described by the following equation different from eq. 5 : $\mathrm{LnL}_{3}(\mathrm{o})+\mathrm{S}_{(0)} \leftrightarrow \mathrm{LnL}_{3} \cdot \mathrm{S}_{(0)}$

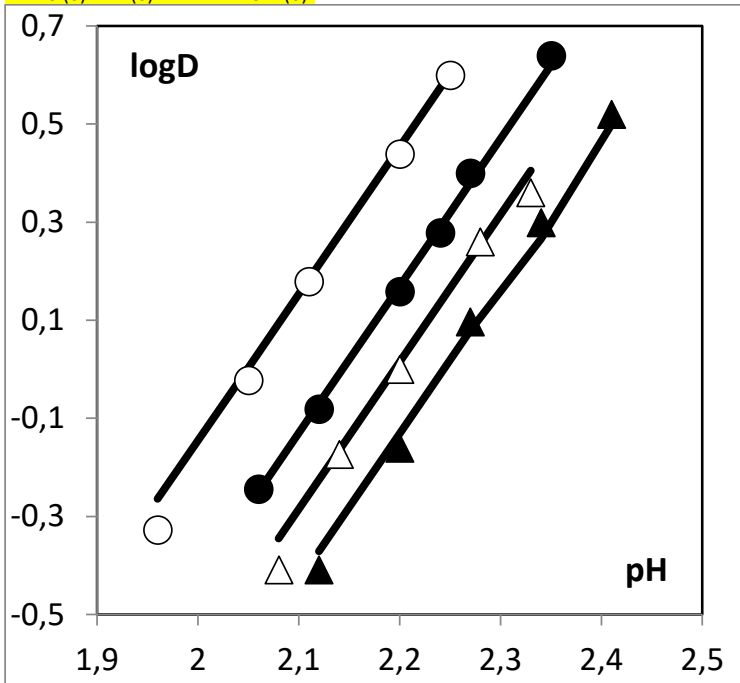

Fig. 6. Distribution coefficient for La towards $\left[\mathrm{C}_{1} \mathrm{C}_{4} i m\right]\left[T f_{2} \mathrm{~N}\right]$, using $\mathrm{HL}+\mathrm{S}_{\mathrm{IV}}$ mixtures, as a function of $\mathrm{pH}$. Symbols: Experimental data. $\mathrm{O}:[\mathrm{HL}]=7 \times 10^{-3} \mathrm{M}$ and $\left[\mathrm{S}_{\mathrm{IV}}\right]=7 \times 10^{-4} \mathrm{M} ; \bullet:[\mathrm{HL}]=5 \times 10^{-3} \mathrm{M}$ and $\left[\mathrm{S}_{\mathrm{IV}}\right]=10^{-4} \mathrm{M} ; \Delta:[\mathrm{HL}]=5 \times 10-3 \mathrm{M}$ and $\left[\mathrm{S}_{\mathrm{IV}}\right]=$ $5 \times 10^{-4} \mathrm{M} ; \boldsymbol{\Delta}:[\mathrm{HL}]=5 \times 10^{-3} \mathrm{M}$ and $\left[\mathrm{S}_{\mathrm{IV}}\right]=7 \times 10^{-4} \mathrm{M}$.

\section{Discussion}

To bring additional material to the discussion, we will refer to the results previously obtained in a comparative study implying a different, although closely related synergistic couple, named $\left(\mathrm{HL}^{\prime}, \mathrm{S}_{\mathrm{III}}\right)$ where $\mathrm{HL}^{\prime}$ stands for 3-methyl-1-phenyl-4-(4trifluoromethylbenzoyl)-pyrazol-5-one and where $S_{\text {III }}$ is for 5,11,17,23-tetra-tert-butyl-25,26,27tris(dimethylphosphinoylpropoxy)-28-hydroxy-calix[4]arene, (Fig. S20). ${ }^{33}$ The sole difference between $\mathrm{HL}$ and $\mathrm{HL}^{\prime}$ lies in the $\mathrm{CF}_{3}$ group appended to $\mathrm{HL}^{\prime}$ and a phenyl group tethered to $\mathrm{HL}$. On another hand, the differences between $\mathrm{S}_{\text {III }}$ and $\mathrm{S}_{\text {IV }}$ lie in the length of the carbon chain linking the lower calixarene rim and the $\mathrm{P}=\mathrm{O}$ group and also in the number of $\mathrm{P}=\mathrm{O}$ groups (either 3 or 4). The latter is indicated as roman subscript for the sake of easiness. Extraction data for $\mathrm{La}(\mathrm{III})$ in $\mathrm{CHCl}_{3}$ and $\left[\mathrm{C}_{1} \mathrm{C}_{4} \mathrm{im}\right]\left[\mathrm{Tf}_{2} \mathrm{~N}\right]$ are gathered in Table 4.

The substitution of $-\mathrm{CF}_{3}$ group $\left(\log K_{\mathrm{L}}=-3.24^{33}\right)$ in the fourth position of the benzoyl moiety in the acylpyrazolone molecule with $-\mathrm{C}_{6} \mathrm{H}_{5}$ group diminishes the extraction efficiency $\left(\log K_{\mathrm{L}}=-6.21\right)$ of $\mathrm{La}(\mathrm{III})$ and this increase of ca. three orders of magnitude is almost similar for the five lanthanoids investigated when $\mathrm{CHCl}_{3}$ is applied as diluent. This large quantitative difference is obtained with an identical extraction mechanism, i.e. the involvement of four ligand units, three being deprotonated to insure charge balance, eq. 1. For $\mathbf{H L}$, the values of $\log K_{\mathrm{L}}$ are approximately $1.60,1.70$ and 2.0 logarithmic units lower than those obtained with 3-methyl-4-(4-methylbenzoyl)-1-phenyl-pyrazol-5-one (HPMMBP, $\left.\mathrm{p} K_{\mathrm{a}}=4.02\right)$, 3-methyl4-benzoyl-1-phenyl-pyrazol-5-one ( $\left.\mathrm{HP}, \mathrm{p} K_{\mathrm{a}}=3.92\right)$ and 3-methyl-1-phenyl-4-(4-trifluoromethylbenzoyl)-pyrazol-5-one 
(HPMFBP, $\mathrm{p} K_{\mathrm{a}}=3.52$ ) respectively. ${ }^{18}$ The substitution of a hydrogen atom in the fourth position of the benzoyl moiety in the acylpyrazolone molecule with a phenyl $\left(\mathrm{C}_{6} \mathrm{H}_{5}-\right)$ group diminishes the extraction efficiency as compared with the case when HP was used as a chelating extractant. ${ }^{46}$ Obviously, in chloroform, the lanthanoid extraction behaviour is dramatically influenced by the 4-acylpyrazolone substituents.

Table 4. Comparison of extraction parameters of the used systems in $\mathrm{CHCl}_{3}$ and $\left[\mathrm{C}_{1} \mathrm{C}_{4}\right.$ im $]\left[\mathrm{Tf}_{2} \mathrm{~N}\right]$ for $\mathrm{La}(\mathrm{III})$ extraction from $\mathrm{HCl}$ medium.

\begin{tabular}{|c|c|c|c|c|c|c|c|}
\hline \multirow{2}{*}{ system } & \multicolumn{3}{|c|}{$\mathrm{CHCl}_{3}$} & \multicolumn{4}{c|}{$\left[\mathrm{C}_{1} \mathrm{C}_{4} \mathbf{i m}^{+}\right]\left[\mathrm{Tf}_{2} \mathrm{~N}^{-}\right]$} \\
\cline { 2 - 8 } & $\log K_{\mathrm{L}}$ & $\log K_{\mathrm{LS}}$ & $\mathrm{SC}$ & $\log K_{\mathrm{L}}$ & $\log K_{\mathrm{S}}$ & $\log K_{\mathrm{LS}}$ & $\mathrm{SC}$ \\
\hline $\mathrm{HL}-\mathrm{S}_{\mathrm{IV}}$ & -6.31 & -1.24 & 3.54 & -2.2 & 3.38 & 3.44 & 2.45 \\
\hline $\begin{array}{l}\mathrm{HL}_{\mathrm{F}}- \\
\mathrm{S}_{\mathrm{III}}{ }^{31}\end{array}$ & -3.24 & 1.22 & 3.13 & -2.33 & 3.30 & 3.34 & 2.52 \\
\hline
\end{tabular}

In chloroform, none of the two calixarenes extracts Ln ions significantly under the experimental conditions but, when used in conjunction with either $\mathrm{HL}^{\prime}\left(\mathrm{S}_{\|}\right.$and $\mathrm{S}_{\mathrm{III}}$ ) or $\mathrm{HL}\left(\mathrm{S}_{\mathrm{IV}}\right)$, they offer a large synergism, the larger SC value being for the extractant couple HL-S . As is illustrated in Fig. 7, the structural differences in the ligands do not substantially distort the SC vs. Ln plots that are parallel to each other but the mixture $\mathrm{HL}-\mathrm{S}_{\mathrm{IV}}$ gives rise to a significant improvement of the extraction. In two examined cases, the synergistic extraction proceeds through the formation of a mixed complex with stoichiometry 1:3:1 for metal, acidic and neutral ligand, respectively. This is a rather classical situation in molecular solvents ${ }^{18,33,46}$ and justifies the search for better acidic ligands, better neutral ligands, then better synergism through minute changes of chemical structures in a given family.

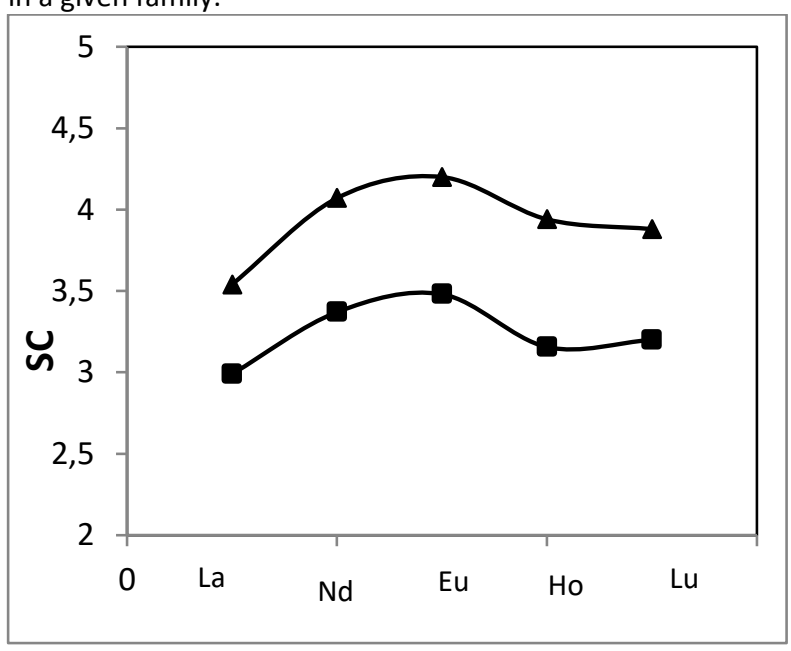

Fig. 8. Comparison of the synergistic coefficient obtained using two different mixtures $\mathrm{HL}-\mathrm{S}$ in chloroform along the $\mathrm{Ln}$ series. $\boldsymbol{\Delta}: \mathrm{HL}-\mathrm{S}_{\mathrm{IV}} ; \mathbf{m}: \mathrm{HL}^{\prime}-\mathrm{S}_{\mathrm{III}}$

The situation is very different in the IL medium and can be discussed along three complementary lines.

First, as already obtained in many cases with various types of ligands ${ }^{53,54}$ the replacement of $\mathrm{CHCl}_{3}$ by the ionic liquid leads to an impressive increase in the individual extraction capabilities: a given ligand concentration leads to an dramatically enhanced distribution ratio in IL as compared to $\mathrm{CHCl}_{3}$. This experimental fact that is also expressed in the $\log \mathrm{K}$ values. The $\log K_{\mathrm{L}}$ value of $\mathrm{La}$ (III) is ca. four orders of magnitude higher than that in $\mathrm{CHCl}_{3}$, Table 4 . The increased extraction brought about by changing the solvent is far above what could be expected from structural changes in the pyrazolone family. The extraction mechanism involves three $\mathrm{HL}$ units $\left(\mathrm{LnL}_{3}\right)$ instead of four in chloroform $\left(\mathrm{LnL}_{3} \cdot \mathrm{HL}\right)$. In the IL phase, it has to be noted that the calixarene moieties obey the same mechanism, again with the involvement of one ligand unit, eq. 10. With the increased number of systems studied in IL phases, huge enhancements in extraction abilities and changes in extraction mechanisms when replacing molecular solvents by IL media tend to become well-recognized behaviors and our data are in line with other works published in the field. ${ }^{26}$

Second, notwithstanding the above, the most striking difference between $\mathrm{CHCl}_{3}$ and $\left[\mathrm{C}_{1} \mathrm{C}_{4} \mathrm{im}^{+}\right]\left[\mathrm{Tf}_{2} \mathrm{~N}^{-}\right]$extraction experiments is the fact that the nature of 4-phenyl terminal group $\left(\mathrm{CF}_{3}\right.$ or $\mathrm{Ph}$ ) has a very limited effect onto the log $K_{\mathrm{L}}$ value in IL: - 2.16 (HL) or $-2.33\left(\mathrm{HL}^{\prime}\right)$. The calixarene neutral compounds $\mathrm{S}_{\mathrm{IV}}$ and $\mathrm{S}_{\mathrm{III}}$ have also rather similar extraction powers in $\left[\mathrm{C}_{1} \mathrm{C}_{4} \mathrm{im}^{+}\right]\left[\mathrm{Tf}_{2} \mathrm{~N}^{-}\right]$ ( $\log K_{\mathrm{S}}$ values equal to 3.38 and 3.30, respectively). In other words, that would mean that the search for better acidic ligands based on structural refinements in a given chemical family, as has been done for years in view of extraction towards molecular solvents, may not be a major objective in IL media. As is demonstrated, even "bad" ligands in molecular solvents could have 
a decent revival in ILs as is the case for HL. This should impulse a re-examination of ligand libraries in order to bring to light compounds previously tagged as "inefficient". Although quite disappointing on a chemical view this surprising effect of ILs will certainly save time and money in the future. In particular, we may imagine that ligands that have been rejected on the basis of poor extraction abilities, despite their good radiolysis resistance, may be of interest in some nuclear applications. Clearly, selection criteria are reshuffled in ILs. However, at the moment, data of this kind are too scarce to derive general rules and we note that similar individual extraction efficiencies for structurally related compounds not always get verified in IL media. For example, Okamura and co-workers ${ }^{55}$ have found recently that the extraction efficiencies of La, Eu and Lu cations using $\left[\mathrm{C}_{1} \mathrm{C}_{4} \mathrm{im}^{+}\right]\left[\mathrm{Tf}_{2} \mathrm{~N}^{-}\right]$with $\mathrm{Htta}$ (2-thenoyltrifluoroacetone, $\left.\mathrm{p} K_{\mathrm{aw}}=6.23^{56}\right)$ or Hnta (2-naphthoyltrifluoroacetone, $\mathrm{p} K_{\mathrm{aw}}=$ $6.35^{57}$ ) alone are quite similar but very different from that with $\mathrm{Hba}$ (benzoylacetone, $\mathrm{p} K_{\mathrm{aw}}=8.96^{58}$ ) alone. The authors ascribed these results to the substituent effect of the $\mathrm{CF}_{3}$ group (in common for $\mathrm{Htta}$ and $\mathrm{Hnta}$ ), as is usually acknowledged in conventional organic solvent systems. ${ }^{15}$ Okamura et al..$^{55}$ have also reported that the synergistic effect for Eu(III) and Lu(III) in the Hba-TOPO (trioctylphosphine oxide) system is considerably larger than that in the Hnta-TOPO system but this is consistent with the $\mathrm{p} K_{\mathrm{a}}$ values of the acidic chelating extractants. The mixtures containing the more weak acidic ligand generates a unique and large synergism in molecular diluents ${ }^{47,48}$ and in IL. ${ }^{55}$

Third, as concerns the synergistic effects in IL medium, the two systems under comparison ( $\mathrm{HL}-\mathrm{S}_{\mathrm{IV}}, \mathrm{SC}=2.45 ; \mathrm{HL}^{\prime}-\mathrm{S}_{\mathrm{III}}, \mathrm{SC}=$ 2.52) display almost identical efficiency. Meanwhile, the $\mathrm{SCs}$ in $\left[\mathrm{C}_{1} \mathrm{C}_{4} i \mathrm{~m}\right]\left[\mathrm{Tf}_{2} \mathrm{~N}\right]$ are somewhat lower than the equivalent data in $\mathrm{CHCl}_{3}$ (see table 4). In our previous work, ${ }^{33}$ we focussed on the lowering of the SC values when passing from $\mathrm{CHCl}_{3}$ to $\left[\mathrm{C}_{1} \mathrm{C}_{4} i \mathrm{~m}\right]\left[\mathrm{Tf}_{2} \mathrm{~N}\right]$ and we ascribed it to two factors: already large values of the individual extraction efficiencies and the ease of solubilisation of watered complexes in IL phase, that renders neutral ligands not mandatory for transfer to the IL phase. These two arguments are still valid in the present case. Although the gain in synergism in IL media is not as good as in chloroform, extraction efficiencies via synergistic couples (acidic/neutral) in IL are far above those in $\mathrm{CHCl}_{3}$. As this increase is solely ascribable to the IL, this class of solvents is clearly ahead in the search for better extracting systems, based on both efficiencies and ecological criteria.

Finally, the comparison of the data for separation factors shows that the selectivity and not only the extractability is again better in the IL medium (see table 3). Usually (i.e. in molecular solvents), the separation becomes poorer as the extractability increases. $47,48,59$ It has also been observed for some $\beta$-diketones that the selectivity decreases with increasing the extractant acidity i.e. lower $\mathrm{p} K_{\mathrm{a}}$ values. ${ }^{60}$ This finding reveals that the combination of an appropriate acidic chelating agent and a hydrophobic IL leads to the improvement of the mutual separation for $4 \mathrm{f}$-ions in ILs.

\section{Conclusions}

The five selected lanthanoid ions are extracted by the $\mathrm{HL}-\mathrm{S}_{\mathrm{IV}}$ combination as $\mathrm{LnL}_{3} \cdot \mathrm{S}$ species using $\mathrm{CHCl}_{3}$. The large synergistic effect does not vary significantly along the lanthanoid series, but the values of the overall equilibrium constant $K_{\mathrm{L}, \mathrm{S}}$ increase with increasing atomic numbers of the metals. The synergistic enhancements produced using $\mathrm{CHCl}_{3}$ as organic media do not depend to a great extent on the nature of para substituents of 4-aroyl-3-methyl-1-phenyl-pyrazol-5-ones (for $\mathrm{La}$ (III): SC $=3.54$ $\left(-\mathrm{C}_{6} \mathrm{H}_{5}\right.$ group, this work) and $\mathrm{SC}=3.13$ (presence of $\left.-\mathrm{CF}_{3}{ }^{33}\right)$ ). The obtained $\log K_{\mathrm{L}, \mathrm{S}}$ values with 4-phenyl terminal group are smaller due to two factors, the steric hindrance and acid dissociation constants of the 4-acylpyrazolones.

All ligand tested alone (either neutral or acidic) display a dramatic enhancement of their individual extraction efficiencies in the IL diluent. The system $\mathrm{HL}-\mathrm{S}_{\mathrm{VV}}$ in $\left[\mathrm{C}_{1} \mathrm{C}_{4} \mathrm{im}\right]\left[\mathrm{Tf}_{2} \mathrm{~N}\right]$ provides the advantage of high $\log K_{\mathrm{L}, \mathrm{S}}(3.44)$ at rather lower pH values of the aqueous phase (1.90-2.30) for $\mathrm{La}^{3+}$ ions. The observed extraction mechanism in the two systems (using $\mathrm{CHCl}_{3}$ and IL) including phosphorus-containing calix[4]arene as synergistic agent and the para-substituted 4-aroyl-3-methyl-1-phenylpyrazol-5-one is identical. The lanthanoids' extraction behavior in the IL medium is influenced neither qualitatively nor quantitatively by the nature of the 4-acylpyrazolone substituents. The calculated equilibrium values are more or less unchanged: $-\mathrm{C}_{6} \mathrm{H}_{5}\left(\log K_{\mathrm{L}, \mathrm{S}}=3.44\right)$, and $-\mathrm{CF}_{3}\left(\log K_{\mathrm{L}, \mathrm{S}}=3.34^{33}\right)$, and the corresponding SCs are also similar.

Considering the negligible impact of the chemical structure of the acidic and neutral ligands investigated in this work on synergistic extraction, one may eagerly wonder what could be the lever arms at our disposal to further improve the -already excellent- extraction efficiencies of (HL-S) synergistic systems in IL media. In a first step, understanding what are the physicochemical parameters underlying such effect is mandatory. To our opinion, ${ }^{33}$ part of the reasons of the levelling up of the synergistic effect should be found in the use of an IL medium accepting large amounts of water in its bulk. Therefore, we would speculate that using more hydrophobic ILs of the imidazolium family, for example $\left[\mathrm{C}_{1} \mathrm{C}_{10} \mathrm{im}\right]\left[\mathrm{Tf}_{2} \mathrm{~N}\right],{ }^{32}$ differences in chemical structures of the ligands would lead to noticeable differences in both individual extraction efficiencies and synergistic effects. However, this might be at the cost of an important decrease of the overall extraction, as already observed in other extraction systems. ${ }^{61}$ Further work on this question is under progress in our group.

\section{Acknowledgements}

The authors are grateful to FP7-PEOPLE-Marie Curie Actions-IEF for the financial support of the project INNOVILLN (622906) 2014-2016.

\section{References}

1. A. Danil de Namor, T. Pawlowski, New J. Chem., 2011, 35, 37. 
2. J. Mathur, Solv. Ext. Ion Exch. 1983, 1, 349.

3. C. A. Blake, C. F. Baes, and C. F. Coleman, in Second International Conference on the peaceful uses of Atomic Energy, Vienna, Austria, 1959), p. 289.

4. H. Irving and D. N. Edington, J. Inorg. Nucl. Chem. 1960, 15, 158.

5. A. H. Bond, M. L. Dietz, and R. Chiarizia, Ind. Eng. Chem. Res. 2000, 39, 3442.

6. Y. Marcus and A. S. Kertes, in Ion Exchange and solvent extraction of metal complexes (Wiley Interscience, New York, 1969), p. 815.

7. M. Atanassova and I. L. Dukov, Sep. Sci. Technol. 2005, 40, 1103.

8. I. Dukov and M. Atanassova, Hydrometallurgy 2003, 68, 89.

9. M. A. Petrova, V. I. Lachkova, N. G. Vassilev, and S. G. Varbanov, Ind. Eng. Chem. Res. 2010, 49, 6189.

10. J. Old, A. Danopolos, S. Winston, New J. Chem., 2003, 27, 672.

11. N. Dung, R. Ludwig, New J. Chem., 1999, 23, 603.

12. Z. Kolarik, Chem. Rev. 2008, 108, 4208.

13. F. Lewis, L. Harwood, M. Hudson, M. Drew, J. Desreux, G. Vidick, N. Bouslimani, G. Modolo, A. Wilden, M. Supula, T.-H. Vu, J.-P. Simoni, J. Am. Chem. Soc., 2011, 133, 13093.

14. A. Bhattacharyya, S. Ansari, T. Gadly, S. Ghosh, M. Mohapatra, P. Mohapatra, Dalton Trans. 2015, 44, 6193.

15. K. Binnemans, in Handbook on the Physics and Chemistry of Rare Earths, edited by K. A. Gschneidner and J. C. G. Bünzli (Elsevier, Amsterdam, 2005), Vol. 35.

16. K. Nash and M. P. Jensen, in Handbook on the Physics and Chemistry of rare Earths (Elsevier Science, 2000), Vol. 28, p. 311.

17. Yu. Zolotov, A. M Kuzmin, Ekstraktsia acylpirazolonami, Nauka, Moskva, (1977).

18. M. Atanassova, V. Kurteva, L. Lubenov, S. Varbanov, and I. Dukov, Sep. Pur. Technol. 2012, 95, 58.

19. C. D. Gutsche, in Calixarenes for separations, edited by G. J. Lumetta, R. D. Rogers and A. S. Gopalan (ACS, Washington, 2000), Vol. 757.

20. J. Atwood, S. Dalgaro, M. Hardie, C. Rastou, New J. Chem., 2004, 28, 326.

21. P. Georghiou, S. Rahman, G. Valluru, I. Dawe, S. Rahman, A. Alodhagb, L. Beaulieu, New J. Chem., 2013, 37, 1298.

22. E. Macerata, F. Castiglione, W. Panzeri, M. Mariani, F. Sanzone, A. Castani, A. Mele, New J. Chem., 2010, $34,2552$.

$23 . \quad$ N. Plechkova and K. R. Seddon, Chem. Soc. Rev. 2008, 37, 123.

24. S. Pandey, G. Baker, L. Sze, S. Pandey, G. Kamath, H. Zhao, S. Baker, New J. Chem., 2013, 37, 909.

25. K. Binnemans, Chem. Rev. 2007, 107, 2592.

26. I. Billard, in Handbook on the Physics and Chemistry of Rare earth, edited by J. C. G. Bünzli and V. K. Percharsky (Elsevier, 2013), Vol. 43.

27. J. Boudesocque, A. Mohamadou, L. Dupont, New J. Chem., 2014, 38, 5573.

28. I. Billard, A. Ouadi, and C. Gaillard, Anal. Bioanal. Chem. 2011, 400, 1555.

29. N. Papaiconomou, I. Billard, and E. Chainet, RSC Adv. 2014, 4, 48260.

30. S. Dai, Y. H. Yu, and C. E. Barnes, J. Chem. Soc., Dalton Trans. 1999, 1201.

31. Z. Kolarik, Solvent Extr. Ion Exch. 2013, 31, 24.

32. M. Atanassova, V. Mazan, I. Billard, ChemPhysChem. 2015, 16, 1703.

33. M. Atanassova, V. Kurteva, L. Lubenov, and I. Billard, RSC Advances 2014, 4, 38820.

34. F. Manetti, M. Magnani, D. Castagnolo, L. Passalacqua, M. Botta, F. Corelli, M. Saddi, D. Deidda, and A. D. Logu, Chem MedChem 2006, 1,973.

35. B. S. Jensen, Acta Chem. Scand. 1959, 13, 1668.

36. L. Saulinier, S. Varbanov, R. Scopelliti, M. Elhabiri, and J. C. G. Bünzli, J. Chem. Soc., Dalton Trans. 1999, 22, 3919.

37. I. Billard and S. Georg, Helv. Chim. Acta 2009, 92, 2227.

38. S. B. Savvin, Arsenazo III, Atomodat, Moskva, (1966).

39. J. N. Mathur, Solv. Ext. Ion Exch. 1990, 8, 629.

40. P. B. Santhi, M. L. P. Reddy, T. R. Ramamohana, A. D. Damodarana, J. N. Mathur, M. S. Murali, and R. H. Iyer, Solv. Ext. Ion Exch. 1994, 12, 633.

41. Y. Albinsson, Acta Chem. Scand. 1989, 43, 919.

42. A. N. Turanov, V. V. Karandashev, A. V. Kharlamov and N. A. Bondarenko, Solvent Extr. Ion Exch. 2014, 32, 492.

43. A. Zhang, Solv. Ext. Ion Exch. 2001, 19, 925.

44. M. Atanassova, V. Lachkova, N. Vassilev, S. Varbanov, I. Dukov, Polyhedron 2010, 29, 655.

45. F. Ramirez, S. Varbanov, J.-C. G. Bünzli, R. Scopelliti, Inorg. Chim. Acta 2011, 378, 163.

46. M. Atanassova, V. Lachkova, N. Vassilev, S. Varbanov, and I. Dukov, J. Incl. Phenom. Macrocyl. Chem. 2007, 58, 173.

47. M. Atanassova, Solv. Extr. Ion Exch. 2009, 27, 159.

48. M. Atanassova, Microchim. Acta 2011, 174, 175.

49. X. Sun, Y. Ji, F. Hu, B. He, J. Chen, and D. Li, Talanta 2010, 81, 1877.

50. M. Sypula, A. Ouadi, C. Gaillard, and I. Billard, RCS Adv. 2013, 3, 10736.

51. F. Ramirez, T. Tosheva, E. Tashev, E. Villafana, S. Shenkov, S. Varbanov, Polyhedron, 2013, 56, 123-133.

52. M. R. Yaftian, M. Burgard, D. Matt, C. B. Dieleman, and F. Rastegar, Solv. Ext. Ion Exchange 1997, 15, 975.

53. N. Hirayama, H. Okamura, K. Kidani, and H. Imura, Anal. Sci. 2008, 24, 697.

54. A. Stojanovic and B. K. Keppler, Sep. Sci. Technol. 2012, 47, 189.

55. H. Okamura, H. Takagi, T. Isomura, K. Morita, H. Nagatani, and H. Imura, Anal. Sci. 2014, 30, 323.

56. A. K. De and S. M. Khopkar, J. Sci. Ind. Des. 1962, 21A, 131.

57. W. L. F. Armarego and C. L. L. Chai, Purification of laboratory chemicals (Elsevier, 2013).

58. J. Stary and H. Freiser, Equilibrium constants of liquid-liquid distribution reactions. Part IV: Chelating extractants (Pergamon Press, Oxford, 1978).

59. R. Pavithran and M. L. P. Reddy, Radiochim. Acta 2004, 92, 31. 
60. A. Messaoudi, K. Torkestani, G. Goetz-Grandmont, and J. P. Brunette, J. Radioanal. Nucl. Chem. 1996, 208, 123.

61. M. L. Dietz and D. C. Stepinski, Talanta 2008, 75, 598. 